\title{
Terahertz Spectroscopy of Misfolded Proteins in Bio-Tissue
}

\author{
Gretel M. Png ${ }^{\mathrm{a}}$, Robyn Flook ${ }^{\mathrm{b}}$, Brian W.-H. Ng${ }^{\mathrm{a}}$, and Derek Abbott ${ }^{\mathrm{a}}$ \\ ${ }^{a}$ School of Electrical and Electronic Engineering, University of Adelaide, SA 5005, Australia \\ ${ }^{\mathrm{b}}$ South Australian Brain Bank, Centre for Neuroscience, Flinders University, SA 5042, Australia
}

\begin{abstract}
Proteins in living organisms must fold in order to carry out their biological function. However some proteins misfold to become unwanted deposits. Understanding the causes and mechanics of protein folding is immensely important in the study of diseases which are caused by protein misfolding. This abstract reports on a novel study which uses terahertz (THz) spectroscopy to probe misfolded proteins in excised diseased human brain tissue. Our early results show distinction in the $\mathrm{THz}$ absorption spectra, which could be attributed to pathological changes in the diseased tissue.
\end{abstract}

\section{INTRODUCTION}

$\mathrm{P}$ ROTEIN misfolding is attributed as being the cause of a range of diseases that involve an unnatural, accelerated accumulation of protein deposits in tissue. One class of diseases is amyloidosis - a group of disorders characterized by insoluble extracellular protein deposits with internal $\beta$-sheets ${ }^{1,2}$. Two well known diseases in the family of amyloidoses are Alzheimer's disease (AD) and type II diabetes ${ }^{3}$.

Terahertz (THz or T-ray) spectroscopy and imaging have in the past been applied to a wide range of medically-inspired applications. Among these applications, $\mathrm{THz}$ has been shown to be potentially useful as a diagnostic tool for protein sensing and histomorphology studies of healthy and diseased excised tissue $^{4,5}$, where fresh and fixed tissue samples are used. Lyophilized tissue samples from various organs have also been explored ${ }^{6}$. Given the past success of $\mathrm{THz}$ protein sensing, it is expected that the collective vibrational modes of protein deposits found in amyloidosis can be detected in the $\mathrm{THz}$ frequency range.

This novel investigation uses $\mathrm{THz}$ spectroscopy to examine healthy and diseased snap-frozen human brain tissue samples taken from one hemisphere of the human brain. Neuropathological analysis of the contralateral hemisphere $e^{7,8}$ of the same brain has confirmed large numbers of protein deposits consistent with AD. Snap-frozen tissue is used because, in theory, the strong $\mathrm{THz}$ resonant activity of liquid water is suspended when frozen ${ }^{9}$, hence improving confidence that any resonant activity detected with $\mathrm{THz}$ radiation is caused solely by characteristics of the tissue. Snap-frozen tissue also has the advantage of containing smaller ice crystals than tissue frozen in a domestic freezer (slow-frozen), thus snap-frozen tissue samples are expected to suffer from less $\mathrm{THz}$ scattering.

\section{PROTEIN MISFOLDING IN ALZHEIMER'S DISEASE}

In living organisms, protein misfolding results in the formation of extracellular protein deposits. In humans, the accumulation of protein deposits in bio-tissue occurs as part of the natural ageing process. However an unnaturally rapid accumulation of deposits can occur in diseases such as AD, resulting in the functional decline of the bio-tissue. In the middle and late stages of $\mathrm{AD}$, unwanted protein deposits, commonly referred to as plaques and tangles, accumulate in the cerebral cortex where neurons and axons are located ${ }^{10}$. These plaques and tangles disrupt intracellular transport in the cells located between neurons, eventually causing cell death ${ }^{11}$ which leads to the breakage of synaptic pathways between neurons; healthy and intact pathways are vital for normal brain function.

Figure 1a shows an example of neuritic protein plaques and tangles associated with AD. As shown in Fig. 1b, plaques contain fibrillary amyloid protein with $\beta$-pleated sheets, hence the protein is often referred to as amyloid- $\beta$. Plaques and tangles are hallmarks of $\mathrm{AD}^{12}$.
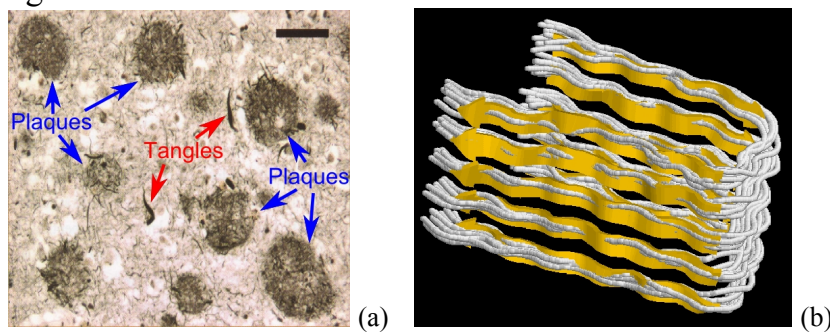

Fig. 1: (a) Neuritic AD plaques with their characteristic amyloid cores, often with radial spikes of fibrillary amyloid. Tangles have a skein-like (thread-like) appearance. The black scale bar represents $100 \mu \mathrm{m}$. After ${ }^{12,13}$ (b) Cartoon diagram of an amyloid- $\beta$ fibril obtained from the Protein Data Bank (PDB), and rendered using Rasmol (PDB ID: 2BEG). The molecule is colored according to its secondary structures: $\beta$-pleated sheets (yellow) and other residues (white). After ${ }^{14}$.

Diagnosis of $\mathrm{AD}$ is currently made on the postmortem identification of high numbers of plaques and tangles in the gray matter of cortical brain regions ${ }^{15,16}$. The development of a non-invasive diagnostic tool for identifying the accumulation of protein plaques during the early stages of $\mathrm{AD}$ would greatly improve medical treatment of the disease, improving the quality of a patient's remaining lifetime. Since 2004, in vivo identification of plaques in humans with Positron Emission Tomography (PET) has been possible through in vivo staining of plaques via intravenous administration of a radioactive dye based on carbon-11 called Pittsburgh compound-B, but this expensive technique is still undergoing human trials and is not yet an early diagnostic tool for $\mathrm{AD}^{17-20}$. Other brain imaging scans, such as Computed Tomography (CT) and Magnetic Resonance Imaging (MRI), are used to rule out brain tumors or blood clots, which may also hinder normal brain function.

Mathematical models have shown that in order to perform in vivo $\mathrm{THz}$ spectroscopy of the cerebral cortex, higher $\mathrm{THz}$ power levels than presently available are needed ${ }^{21,22}$. The most readily available techniques at present are ex vivo $\mathrm{THz}$ studies 
of protein plaques in excised tissue, and $\mathrm{THz}$ spectroscopy of amyloid- $\beta$ protein synthesized in vitro. Results from these studies will contribute towards expanding our limited understanding of $\mathrm{AD}$ pathogenesis.

\section{SAMPLES}

Snap-frozen brain samples are obtained from the South Australian Brain Bank ${ }^{23}$, which is a repository for the storage of human brains donated for medical research. The majority of donors were patients suffering from neurological and/or psychiatric illnesses. The actual cause of death is only confirmed after postmortem autopsies are performed. One hemisphere of each donated brain is fixed in formalin and then sliced coronally; the other hemisphere is also sliced coronally and then snap-frozen. The formalin-fixed hemisphere is pathologically analyzed to identify the cause of death.

Figure 2a shows a $10 \mathrm{~mm}$ thick coronal brain slice with gray and white matter delineated. Healthy gray matter has a thickness of $3.4 \pm 0.3 \mathrm{~mm}^{24,25}$. Plaques and tangles are only present in gray matter, hence only this region is of interest in this study. It is not possible to only extract gray matter from a snap-frozen brain slice because it is too firm. Thawing an entire slice is not an option because the freeze-thaw-freeze cycle may damage the slice, wasting valuable tissue not used in this study.

One solution is to extract a $\sim 15 \mathrm{~mm}$ long core as shown in Fig. $2 \mathrm{~b}$ using a slow-speed trepanning drill with a $7 \mathrm{~mm}$ diameter hollow drill bit. Gray matter is more easily sliced out from this core than from the snap-frozen brain slice.

The cores are taken from three regions in the cerebral cortex of both healthy and diseased brains: superior frontal gyrus (SFG), inferior frontal gyrus (IFG) and cingulate gyrus (CG). These regions are chosen because Bielschowsky silver staining of the exact regions in the formalin-fixed diseased contralateral hemispheres ${ }^{7,8}$ have revealed numerous protein plaques $(\sim 102$ plaques per $\times 250$ microscope magnification field); in healthy brains, no plaques are observed in these regions.

A tissue slicer comprising of two blades spaced apart by a thin washer is used to extract the gray matter from the cores. The final sample is a pellet-like disk of gray matter ("brain disk"). Each disk has two flat surfaces which assist in reducing $\mathrm{THz}$ scattering during measurements.
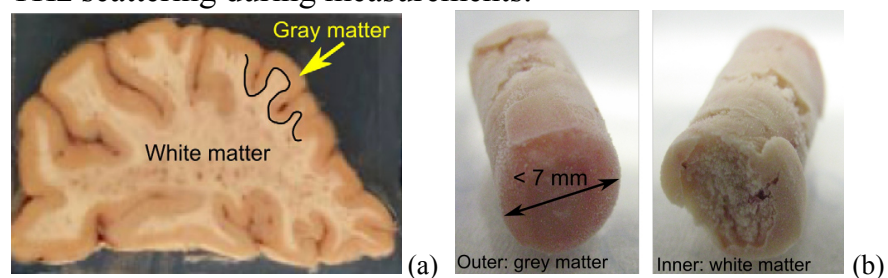

Fig. 2: (a) Blood supply in the gray matter gives it a pinkish-gray hue. Plaques and tangles only accumulate in gray matter; (b) Gray matter is recognized by the pinkish end of each $\sim 15 \mathrm{~mm}$ long core. The paler end is white matter. Gray matter is removed from the core by slicing it with a tissue slicer with two blades.

\section{EXPERIMENT}

Measurements are made with a transmission mode THz Time Domain System (TDS) in conjunction with a closed-cycle cryostat (Janis CCS-450) enclosed inside a nitrogen-purged chamber. Samples are measured in air at $-28^{\circ} \mathrm{C}(245 \mathrm{~K})$ without vacuum evacuation to prevent the samples from lyophilizing.

\section{RESULTS}

Figure 3 shows the $\mathrm{THz}$ absorption coefficients of the brain disks taken from the three regions. All diseased tissue appear to have lower $\mathrm{THz}$ absorption than healthy tissue. However for the SFG tissue, both healthy and diseased tissue experience higher $\mathrm{THz}$ absorption than the other tissue types, implying that THz scattering has occurred. Visual examination of SFG tissue reveals many blood clots which are likely due to ruptured blood vessels; these clots may scatter THz. Repeat measurements of other batches of SFG tissue have produced wildly varying results-SFG tissue requires further investigation.

For the CG and IFG tissue, it is not possible to conclude that any distinction between the healthy and diseased tissue samples is due to a specific type of protein (e.g. amyloid- $\beta$ ). It is possible that the difference is due to the collective response of a variety of known abnormal proteins that accumulate in diseased brain tissue, which for $\mathrm{AD}$ include amyloid- $\beta$, lipofuscin, tau, and glial fibrillary acidic (GFA) protein ${ }^{26}$. Tissue atrophy is also a common occurrence in $\mathrm{AD}$, thus atrophy could have also contributed to the observed differences.

(a) Absorption coefficients of diseased and healthy cingulated gyri (CG)

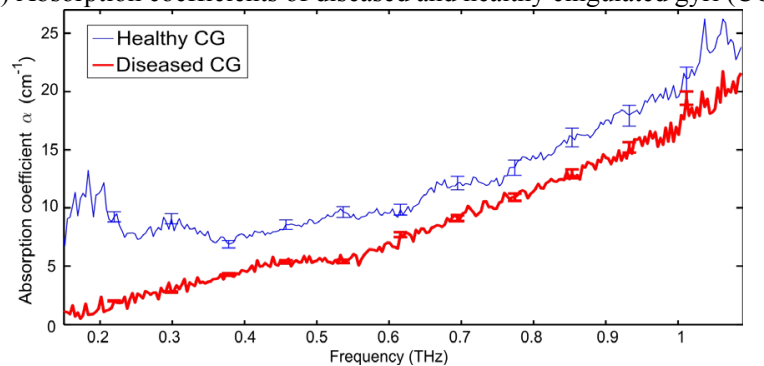

(b) Absorption coefficients of diseased and healthy inferior frontal gyri (IFG)

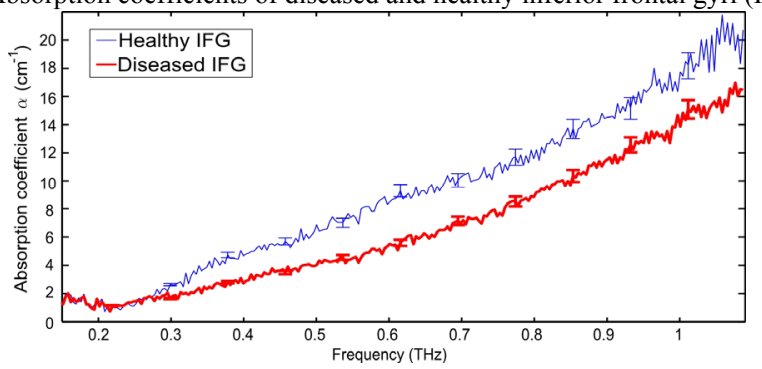

(c) Absorption coefficients of diseased and healthy superior frontal gyri (SFG)

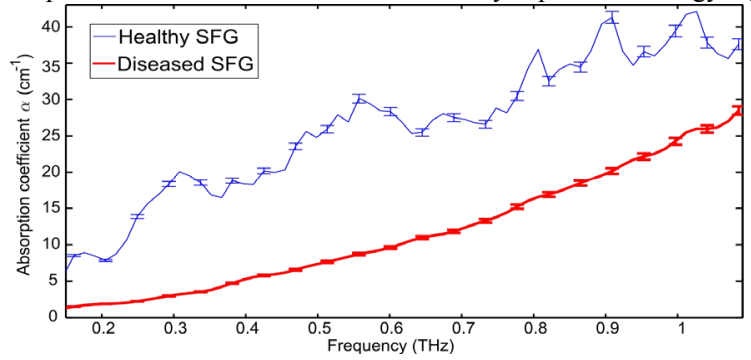

Fig. 3: The error bars account for the uncertainty in thickness of the brain disks (see Section VI). A clear distinction between the absorption coefficients of diseased and healthy tissue is evident. However it is not possible to conclude that this distinction is due to protein plaques in the diseased samples. Diseased brains are often in poor condition due to brain atrophy, hence these changes may be due to difference in brain tissue density or shrinkage in gray matter. 


\section{Challenges AND Future WORK}

Minimal handling of the cores and disks is paramount so as to reduce thawing caused by heat from contact with fingers/gloves, forceps, dishes, etc. This is a particularly difficult endeavor when slicing the cores to ensure the brain disks have flat incident surfaces to the $\mathrm{THz}$ signal. Anatomically matching healthy and diseased tissue samples is also a challenge due to the poor physical condition of many diseased brains. Moreover the thickness of gray matter can vary on a case by case basis, and may be reduced in AD brains, resulting in a mixture of white and gray matter in a brain disk.

Owing to the challenges highlighted above, two alternatives to whole brain tissue are: isolated protein plaques obtained from homogenized brain tissue, and AD biomarkers in body fluids. A parallel study has already been performed on in vitro synthesized proteins with fibrillar structures similar to amyloid- $\beta$ fibrils in $\mathrm{AD}^{27}$. This study has shown that it is possible to differentiate between protein microstructures with different 3-dimensional structures. This work will be extended to include $\mathrm{THz}$ spectroscopy of proteins associated with $\mathrm{AD}$.

\section{CONCLUSION}

These early results involving snap-frozen whole brain tissue are encouraging but many experimental and histological challenges will need to be overcome before $\mathrm{THz}$ spectroscopy can be used confidently to analyze frozen brain tissue for the purpose of studying the pathogens in AD. Given the paucity of knowledge on the etiology of $\mathrm{AD}$, any discovery will contribute to the small but growing pool of scientific knowledge to facilitate advances in the diagnosis and treatment of $\mathrm{AD}$.

\section{ACKNOWLEDGEMENT}

Tissues were received from the South Australian Brain Bank, which is supported by the NH\&MRC.

\section{REFERENCES}

[1] D. R. Booth, M. Sunde, V. Bellotti, C. V. Robinson, W. L. Hutchinson, P. E. Fraser, P. N. Hawkins, C. M. Dobson, S. E. Radford, C. C. F. Blake, and M. B. Pepys, "Instability, unfolding and aggregation of human lysozyme variants underlying amyloid fibrillogenesis," Nature, vol. 385, 1997, pp. 787-793.

[2] J. Näslund, V. Haroutunian, R. Mohs, K. L. Davis, P. Davies, P. Greengard, and J. D. Buxbaum, "Correlation between elevated levels of amyloid $\beta$-peptide in the brain and cognitive decline," Journal of the American Medical Association, vol. 283, 2000, pp. 1571-1577.

[3] S. Y. Tan and M. B. Pepys, "Amyloidosis," Histopathology, vol. 25, 1994, pp. $403-414$.

[4] V. P. Wallace, A. J. Fitzgerald, E. Pickwell, R. J. Pye, P. F. Taday, N. Flanagan, and T. Ha, "Terahertz pulsed spectroscopy of human Basal Cell Carcinoma," Applied Spectroscopy, vol. 60, 2006, pp. 1127-1133.

[5] P. Knobloch, C. Schildknecht, T. Kleine-Ostmann, M. Koch, S. Hoffmann, M. Hofmann, E. Rehberg, M. Sperling, K. Donhuijsen, G. Hein, and K. Pierz, "Medical THz imaging: An investigation of histo-pathological samples," Physics in Medicine and Biology, vol. 47, 2002, pp. 3875-3884.

[6] G. M. Png, J.-W. Choi, B. W.-H. Ng, S. P. Mickan, D. Abbott, and X.-C. Zhang, "The impact of hydration changes in fresh bio-tissue on $\mathrm{THz}$ spectroscopic measurements," Physics in Medicine and Biology, vol. 53, 2008, pp. 3501-3517.
[7] J. Moossy, G. S. Zubenko, A. J. Martinez, G. R. Rao, U. Kopp, and I. Hanin, "Lateralization of brain morphologic and cholinergic abnormalities in Alzheimer's disease," Archives in Neurology, vol. 46, 1989, pp. 639-642.

[8] S. Demeter, D. L. Rosene, and G. W. Van Hoesen, "Commissural connections and symmetry of degeneration in Alzheimer's disease," Archives in Neurology, vol. 46, 1989, pp. 723-724.

[9] P. C. Ashworth, J. A. Zeitler, M. Pepper, and V. P. Wallace, "Terahertz spectroscopy of biologically relevant liquids at low temperatures," presented at Joint 31st International Conference on Infrared and Millimeter Waves and 14th International Conference on Terahertz Electronics (IRMMW-THz), Shanghai, China, 2006, pp. 184.

[10] J. Nolte, The Human Brain: An introduction to Its Functional Anatomy, 5th ed. St. Louis, MO, USA: Mosby Inc., 2002.

[11] J. L. Cummings, The Neuropsychiatry of Alzheimer's Disease and Related Dementias. London, England: Martin Dunitz Ltd., 2003.

[12] S. S. Mirra and B. T. Hyman, "Ageing and dementia," in Greenfield's Neuropathology, vol. 2, D. I. Graham and P. L. Lantos, Eds., 7th ed. London, UK: Arnold, 2002, pp. 195-271.

[13] I. R. A. Mackenzie, "Neuropathology of Alzheimer's disease," in Atlas of Alzheimer's disease, H. H. Feldman, Ed. London, UK: Informa UK Ltd, 2007, pp. 71-81.

[14] T. Lührs, C. Ritter, M. Adrian, D. Riek-Loher, B. Bohrmann, H. Döbeli, D. Schubert, and R. Riek, "3D structure of Alzheimer's amyloid- $\beta(1-42)$ fibrils," Proceedings of the National Academy of Sciences of the United States of America, vol. 102, 2005, pp. 17342-17347.

[15] H. Braak and E. Braak, "Neurofibrillary changes confined to the entorhinal region and an abundance of cortical amyloid in cases of presenile and senile dementia," Acta Neuropathologica, vol. 80, 1990, pp. 479-486.

[16] J. C. Morris, M. Storandt, D. W. McKeel Jr., E. H. Rubin, J. L. Price, E. A. Grant, and L. Berg, "Cerebral amyloid deposition and diffuse plaques in "normal" aging: Evidence for presymptomatic and very mild Alzheimer's disease," Neurology, vol. 46, 1996, pp. 707-719.

[17] W. E. Klunk, H. Engler, A. Nordberg, Y. Wang, G. Blomqvist, D. P. Holt, M. Bergstrom, I. Savitcheva, G.-f. Huang, S. Estrada, B. Ausén, M. L. Debnath, J. Barletta, J. C. Price, J. Sandell, B. J. Lopresti, A. Wall, P. Koivisto, G. Antoni, C. A. Mathis, and B. Långström, "Imaging brain amyloid in Alzheimer's disease with Pittsburgh compound-B," Annals of Neurology, vol. 55, 2004, pp. 306-319.

[18] A. Nordberg, "PET imaging of amyloid in Alzheimer's disease," The Lancet Neurology, vol. 3, 2004, pp. 519-527.

[19] C. C. Rowe, S. Ng, U. Ackermann, S. J. Gong, K. Pike, G. Savage, T. F. Cowie, K. L. Dickinson, P. Maruff, D. Darby, C. Smith, M. Woodward, J. Merory, H. Tochon-Danguy, G. O'Keefe, W. E. Klunk, C. A. Mathis, J. C. Price, C. L. Masters, and V. L. Villemagne, "Imaging $\beta$-amyloid burden in aging and dementia," Neurology, vol. 68, 2007, pp. 1718-1725.

[20] K. E. Pike, G. Savage, V. L. Villemagne, S. Ng, S. A. Moss, P. Maruff, C. A. Mathis, W. E. Klunk, C. L. Masters, and C. C. Rowe, " $\beta$-amyloid imaging and memory in non-demented individuals: Evidence for preclinical Alzheimer's disease," Brain, vol. 130, 2007, pp. 2837-2844.

[21] G. M. Png, S. P. Mickan, and D. Abbott, "Simulation of terahertz radiation in stratified media," SPIE Design Technology, and Packaging II, Brisbane, Australia, vol. 6038, 2005, art. no. 60380M.

[22] W. Withayachumnankul, G. M. Png, X.-X. Yin, S. Atakaramians, I. Jones, H. Lin, B. Ung, J. Balakrishnan, B. W.-H. Ng, B. Ferguson, S. P. Mickan, B. M. Fischer, and D. Abbott, "T-ray sensing and imaging," Proceedings IEEE, vol. 95, 2007, pp. 1528-1558.

[23] Centre for Neuroscience, Flinders University, (accessed: 2009-07-09), http://som.flinders.edu.au/FUSA/NEUROSCIENCE/SABrainBank.htm.

[24] B. Fischl and A. M. Dale, "Measuring the thickness of the human cerebral cortex from magnetic resonance images," Proceedings of the National Academy of Sciences of the United States of America, vol. 97, 2000, pp. 11050-11055.

[25] D. MacDonald, N. Kabani, D. Avis, and A. C. Evans, "Automated 3-D extraction of inner and outer surfaces of cerebral cortex from MRI," NeuroImage, vol. 12, 2000, pp. 340-356.

[26] D. J. Selkoe, "Alzheimer's Disease: Genes, proteins, and therapy," Physiological Reviews, vol. 81, 2001, pp. 741-766.

[27] G. M. Png, R. J. Falconer, B. M. Fischer, H. A. Zakaria, S. P. Mickan, A. P. J. Middelberg, and D. Abbott, "Terahertz spectroscopic differentiation of microstructures in protein gels," Optics Express, vol. 17, 2009, pp. 13102-13115. 